\title{
PREVALENCE AND SEVERITY OF TEMPOROMANDIBULAR DISORDERS AMONG HOUSE OFFICERS AND POST-GRADUATE RESIDENTS OF PRIVATE AND PUBLIC SECTOR MEDICAL AND DENTAL HOSPITALS IN PESHAWAR, PAKISTAN.
}

\author{
Muhammad llyas ${ }^{1}$ Fariha Kifayat ${ }^{2}$ Faryal Gul ${ }^{3}$ Salman Khan $^{4}$ Sumaira Saeed ${ }^{5}$ Adam Khan Danish ${ }^{6}$
}

\begin{abstract}
:
OBJECTIVES:

To evaluate the prevalence and severity of TMDs in house officers and postgraduate students belonging to public and private sector medical and dental colleges.
\end{abstract}

\section{METHODOLOGY:}

This was a cross sectional study carried out from July 2018 to September 2018 in Department of Oral and Maxillofacial Surgery, Sardar Begum Dental College and Hospital, Peshawar. After approval from ethical committee Gandhara University, an informed consent was obtained and Fonseca questionnaire was used to evaluate TMDs from 320 subjects who voluntarily want to participate in the study; selected with equal genders from public and private sectors medical and dental hospitals, Peshawar. Those who have musculoskeletal, neurological, systemic problems and orthodontics treatment subjects were excluded from the study.

\section{RESULTS:}

The age range selected was 22-32 years and the mean age presentation was $26.5 \pm 3.4$ years. Results showed that female postgraduate residents of private sector consider themselves tenser (18.8\%) than others. $70.17 \%$ female house officers of private sector have noticed TMJ clicking and $83.17 \%$ of male house officers clenched or grind their teeth than others.

\section{CONCLUSION:}

The study concluded that mild and moderate TMDs are more common in house-officers and postgraduate residents.

KEYWORDS: Temporomandibular Disorders, Prevalence, Temporomandibular Joint, Fonseca's anamnestic index, Cross-sectional Study.

https://doi.org/10.37762/jgmds.6-1.85

\section{INTRODUCTION:}

Temporomandibular disorders (TMDs) is an aggregate term used to describe the subgroup of painful oral \& maxillofacial disorders that involved the complaint of pain in temporomandibular joint (TMJ) region, fatigue of the oral and maxillofacial

\begin{tabular}{|c|}
\hline Correspondence \\
Muhammad Ilyas \\
Department of Oral and \\
Maxillofacial Surgery \\
Sardar Begum Dental \\
College, Peshawar \\
Email: \\
ilyas_khan526@yahoo.com \\
Phone: 0302-8809637 \\
\hline
\end{tabular}
muscles particularly masticatory muscles, limited mandibular movements and the presence of articular clicking. The etiology of TMDs has been connected to various factors which includes neoplastic growth, immune-mediated systemic disease, traumatic injury, emotional stress, postural changes, dysfunctions of masticatory muscles and adjacent structures, extrinsic and intrinsic changes of TMJ structures, occlusal interference, malocclusion, loss of teeth, bruxism, tooth clenching habits or combination of above factors. ${ }^{1-4}$ Goldstein in 1999 proposed that orthognathic surgery, mandibular fractures, orthodontic treatment and prosthetic rehabilitation may cause changes in TMJ and expose TMDs in more worsening position. ${ }^{5}$ The prevalence of TMDs varies, a high prevalence is seen in adult population with $70-75 \%$ of having at least one sign of TMDs. ${ }^{6}$ The variance in the TMDs may be due to the differences in the ethnic group of population, sampling technique and criteria used for TMDs. ${ }^{7}$ Different assessment tools for TMDs has been established but there is no universal diagnostic criteria has yet been proposed. ${ }^{8-9}$ Fonseca anamnestic index (FAI) is a self- 
administered questionnaire and is considered a low cost, easily applied analytical aid for the diagnosis of TMDs in non-patient population. ${ }^{10}$ Campos et al suggested FAI for TMDs due to its simplicity, speed and cost effectiveness. ${ }^{11}$ Furthermore, FAI also give severity index having less impact from the examiner and less variation in the measures. ${ }^{12}$ In literature no study has been found in Pakistan that showed TMDs in public and private sector medical and dental college's house officers and postgraduate students.

The objective of this study was to determine the prevalence and severity of TMDs in house officers and postgraduate students belonging to public and private sector medical and dental colleges.

\section{METHODOLOGY:}

A cross sectional study was carried out in the Department of Oral \& maxillofacial Surgery, Sardar Begum Dental College \& Hospital, Peshawar from July 2018 to September 2018. Approval from ethical committee of Gandhara University, Peshawar was taken. A total of 320 house officers and post-graduate residents with equal gender were selected. Their age ranged from 22 to 32 years having no history of orthodontic treatment, systemic, musculoskeletal and neurological problems. An informed written consent was taken from the subjects who voluntarily want to participate in the study. Covering letter stating the instructions, rationale and purpose of the study were distributed conveniently amongst the sample of 320 . Fonseca's questionnaire was used to evaluate TMDs in the subjects as shown in the table 1. The same questionnaire was adopted in the previous studies. ${ }^{12-16}$ Fonseca's questionnaire comprises of 10 questions. Participants were requested to select one answer among three i.e. No, sometimes or yes. Each "yes" answer was given 10 value, each "sometimes" answer was 05 and "no" answer value a 0 . The sum of all 10 answer's value was used to classify the TMDs according to Fonseca's anamnestic index as shown in the table 1. The data was analyzed using SPSS 23.0 with $95 \%$ confidence interval. $P \leq 0.05$ was regarded as statistically significant.

Table.1. Fonseca's questionnaire.

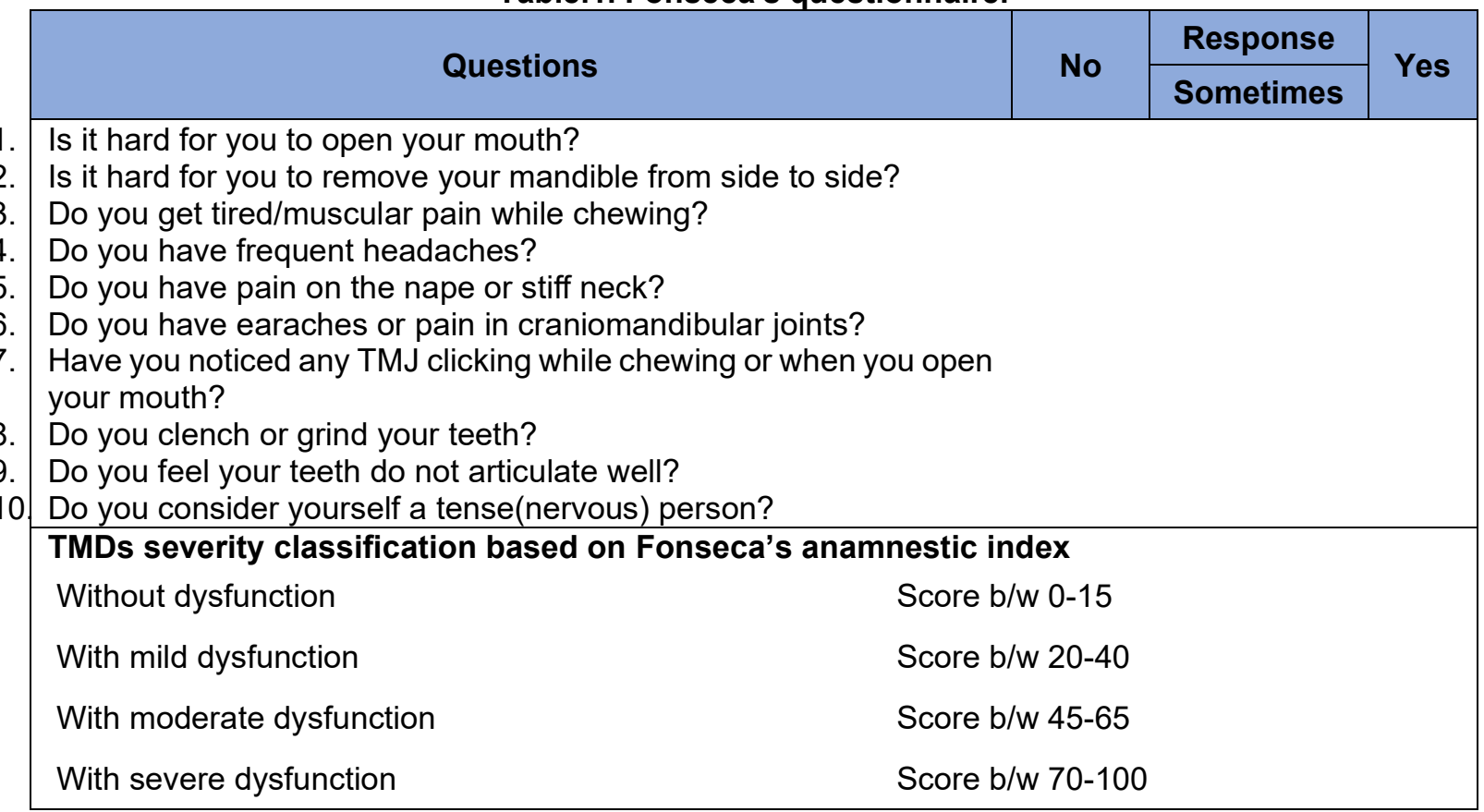

\section{RESULTS:}

The mean age presentation was $26.5 \pm 3.4$ years. Among house officers of public sector male have slightly more severe TMDs (5\%) than female $(2.5 \%)$ and private sector have the same results as that of above. Female postgraduate residents of public sector have more severe TMDs (15\%) than male $(2.5 \%)$ while private sector showed that male $(10 \%)$ are more prone to severe TMDs than female $(5 \%)$ as shown in table 2 . Results are shown in graphs and table 2. 


\begin{tabular}{|c|c|c|c|c|}
\hline & $\begin{array}{c}\text { None } \\
\text { N(\%age) }\end{array}$ & $\begin{array}{c}\text { Mild } \\
\text { N(\%age) }\end{array}$ & $\begin{array}{c}\text { Moderate } \\
\text { N(\%age) }\end{array}$ & $\begin{array}{c}\text { Severe } \\
\text { N(\%age) }\end{array}$ \\
\hline Female House Officers (Public) & $8(20.0)$ & $15(37.5)$ & $16(40.0)$ & $1(2.5)$ \\
\hline Male House Officers (Public) & $6(15.0)$ & $16(40.0)$ & $16(40.0)$ & $2(5.0)$ \\
\hline Female House Officers (Private) & $3(7.5)$ & $16(40.0)$ & $20(50.0)$ & $1(2.5)$ \\
\hline Male House Officers (Private) & $6(15.0)$ & $20(50.0)$ & $12(30.0)$ & $2(5.0)$ \\
\hline Female Postgraduate Residents (Public) & $7(17.5)$ & $11(27.5)$ & $16(40.0)$ & $6(15.0)$ \\
\hline Male Postgraduate Residents (Public) & $4(10.0)$ & $16(40.0)$ & $19(47.5)$ & $1(2.5)$ \\
\hline Female Postgraduate Residents (Private) & $9(22.5)$ & $14(35.0)$ & $15(37.5)$ & $2(5.0)$ \\
\hline Male Postgraduate Residents (Private) & $4(10.0)$ & $10(25.0)$ & $22(55.0)$ & $4(10.0)$ \\
\hline
\end{tabular}

Table.2. Frequency and Percentage of TMDs Severity Based on Fonseca's Anamnestic Index.

Figure.1.Postgraduate (Public) - Male (M) and Female (F)

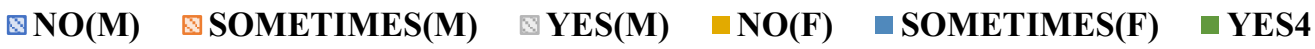

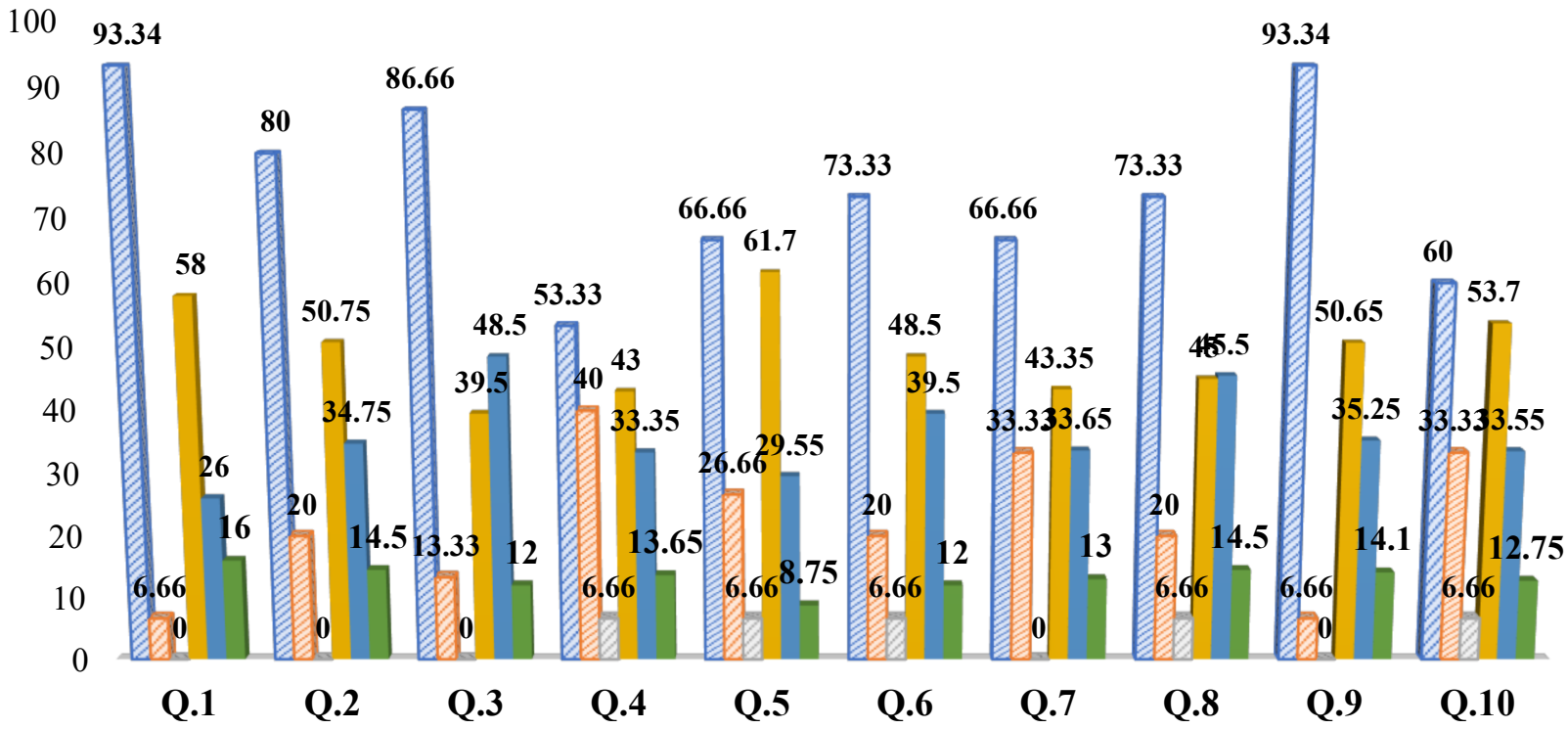

Figure.2.Postgraduate (Private) - Male(M) and Female(F)

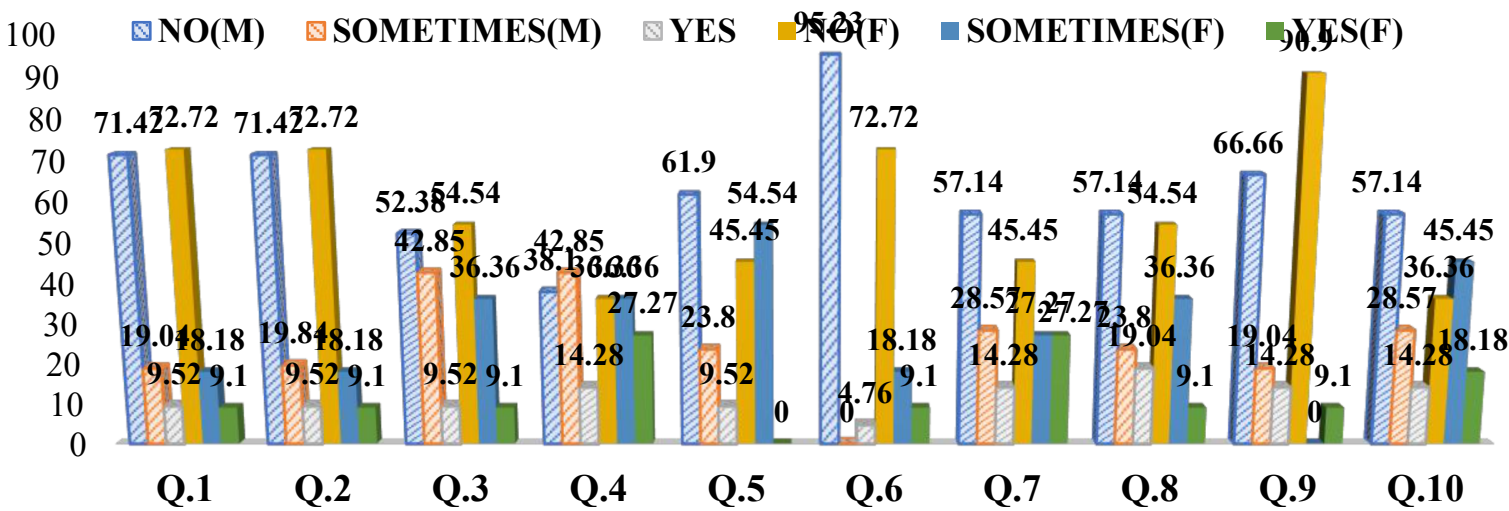


Figure .3.House Officer (Public) - Male (M) and Female (F)

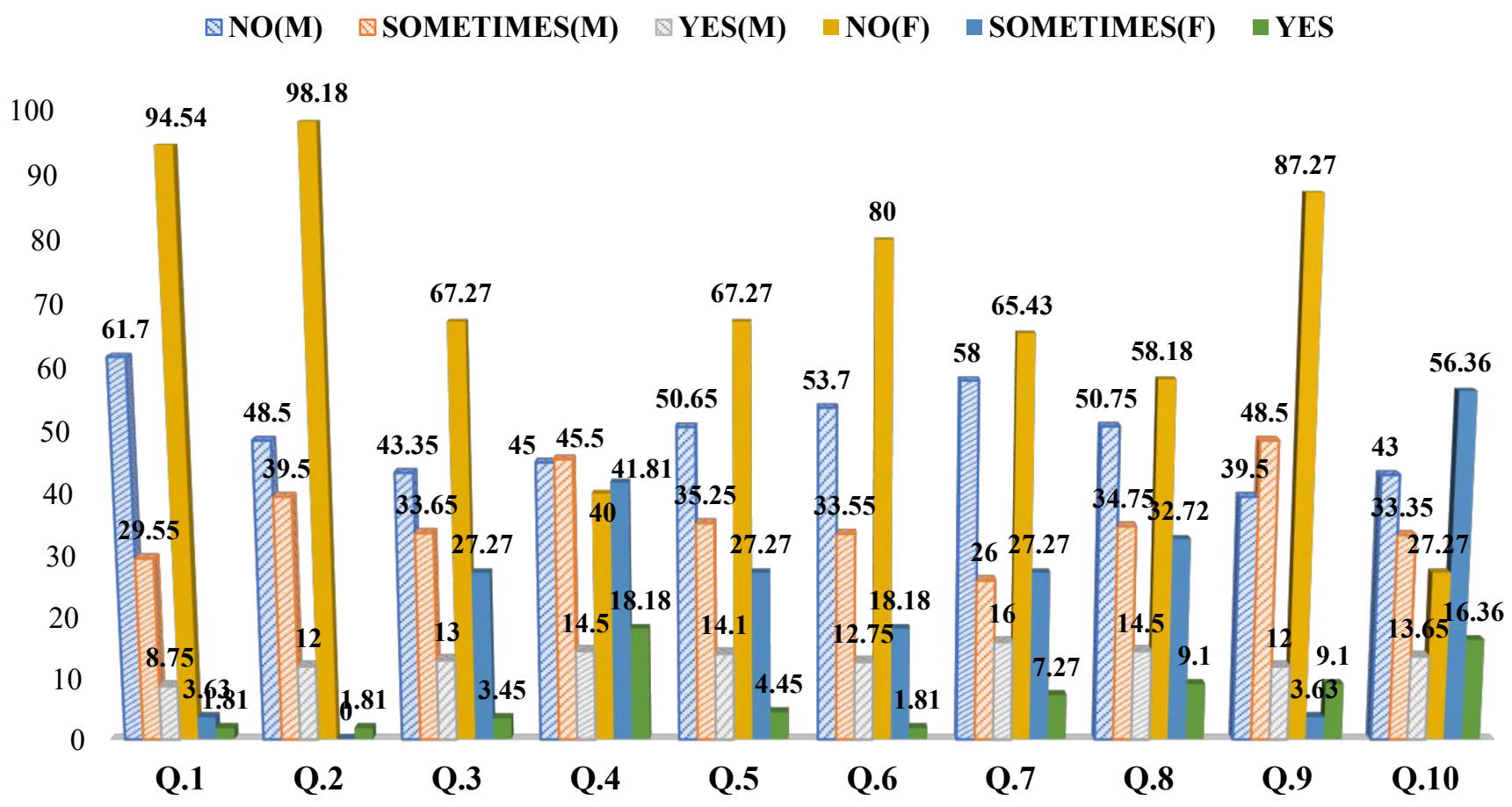

Figure. 4.House Officer (Private) - Male (M) and Female (F)

⿴NO(M) $\quad$ SOMETIMES(M) $\quad$ SOYES(M) $\quad$ NO(F) $\quad$ SOMETIMES(F) $\quad$ YES4

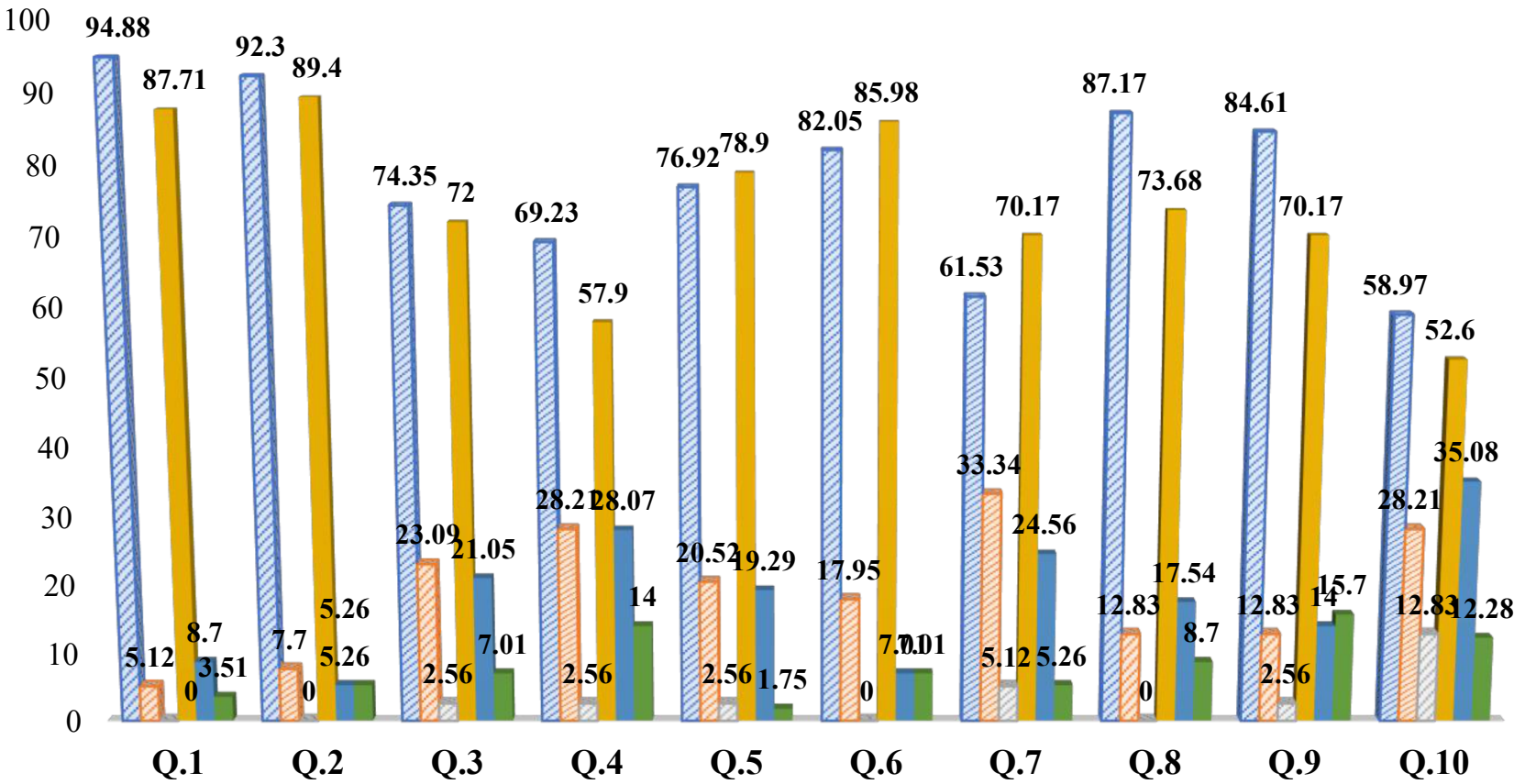

\section{DISCUSSION:}

The study revealed that $70.17 \%$ female house officers of private sector have noticed TMJ clicking than others. This study is in accordance with the study of the Ebrahimi et al ${ }^{15}$ but it is more than that Japanese students, ${ }^{17}$ Brazilian adolescents ${ }^{4}$ or Iranian dental students in another 
study. ${ }^{18}$ It has been reported that joint clicking is considered one of the most prevalent symptom of TMDs. ${ }^{19}$ This may be due to that females go for checkups frequently than males and second consideration in this regard may be hormonal difference that have also been suggested an important factor in TMDs. ${ }^{20}$ The findings of this study suggest that $83.17 \%$ male house officers clenched or grind their teeth in private medical and dental hospitals. This study is in contrast to the study done by Ebrahimi et $\mathrm{al}^{15}$ and is in agreement with other studies. ${ }^{18,21}$ The more prevalent males than females may be due to that males are more cautious about their future during house officer stage of life and clinching has association with TMDs. ${ }^{21,22}$ This investigation this study disclosed that mild and moderate TMDs are more common in both private and public sector's house officers and post graduate residents. This study is consistent with study done by Nomura 12 Bonjardim et al. ${ }^{23}$ Modi et $\mathrm{al}^{13}$ opposes this study in which he revealed that free of TMDs and mild TMDs are more prevalent. The difference could be due to racial, social or ethical background of the subjects. The limitation of the study is that house officers and post graduate residents of medical and dental hospitals were not selected separately. Examination of the TMJ of the subjects was not carried out. The sample size considered for the study was too small for Peshawar region.

\section{CONCLUSION:}

The study concluded that:

1. The prevalence and severity of TMJ are equally distributed in male and female house officers as well as post graduate residents of private medical and dental hospitals.

2. Clicking were more frequent in female house officer of private sectors while clenching or grinding of teeth were more common in male house officers of private sectors.

\section{RECOMMENDATIONS:}

TMDs decline the standard of life. Early diagnosis and prevention of TMDs are challenges for dentists and each attempt should be made to reduce TMDs in medical and dental house officers and postgraduate residents.

\section{REFERENCES:}

1. deSantis TO, Motta LJ, Gonzalez DAB, Ferrari RAM, Fernandes KPS, de Godoy $\mathrm{CHL}$, Alfaya TA, Bussadori SK.Accuracy study of the main screening tools for temporomandibular disorder in children and adolescents.J Bodyw Mov Ther. 2014;18:8791.

2. Manfredini D, Lobbezoo F. Relationship between bruxism and temporomandibular disorders: a systematic review of literature from 1998 to 2008. Oral Surg Oral Med Oral Pathol Oral Radiol Endod. 2010;109:e26e50.

3. Bonjardim LR, Gaviao MB, Pereira LJ, Castelo PM. Anxiety and depression in adolescents and their relationship with signs and symptoms of temporomandibular disorders. Int J Prosthodont. 2005;18:347-52.

4. Bonjardim LR, Gavião MBD, Pereira LJ, Castelo PM, Garcia RCMR. Signs and symptoms of temporomandibular disorders in adolescents. Braz Oral Res. 2005;19(2):938

5. Goldstein BH. Temporomandibular disorders: a review of current understanding. Oral Surg Oral Med Oral Pathol Oral Radiol Endod. 1999;88:379-85.

6. Olivares HG, Saucedo FL, Nova AP. Temporomandibular joint disorder prevalence in resident physicians at the Specialties Hospital «La Raza» National Medical Center. Revista Odontológica Mexicana, 2016; 20(1):8-12.

7. Lee JY, Kim YK, Kim SG, Yun PY.Evaluation of Korean teenagers with temporomandibular joint disorders.J Korean Assoc Oral Maxillofac Surg.2013;39:231-7.

8. Dworkin SF, LeResche L.Research diagnostic criteria for temporomandibular disorders: review, criteria, examinations and specifications, critique.J Carniomandib Disord.1992; 6 (4):301-55.

9. Schiffman E, Ohrbach R,Truelove E,Look J, Anderson G, Goulet JP et al.Diagnostic Criteria for Temporomandibular Disorders (DC/TMD) for clinical and research applications: recommendations of the international RDC/TMD Consortium Network 
and Orofacial Pain Special Interest Group.J Oral Facial Pain Headache.2014; 28 (1):6-27.

10. Da Fonseca DM, Bonfante $G$, Valle $A L, d e$ Freitas SFT. Diagnósticopelaanamnese da disfunçãocraniomandibular.Rev Gauch de Odontol.1994; 4 (1):23-32.

11. Campos JADB, Goncalves DAG, Camparis CM, Speciali JG. Reliability of a questionnaire for diagnosing the severity of temporomandibular disorder.Rev Bras Fisioter.2009; 13 (1):38-43.

12. Nomura K, Vitti M, Oliveira AS, Chaves TC, Semprini M, Siéssere $S$ et al. Use of the Fonseca's questionnaire to assess the prevalence and severity of temporomandibular disorders in Brazilian dental undergraduate.Braz Dent. J.2007; 18 (2): 163-7.

13. Modi P, Shaikh SS, Munde A. A cross sectional study of prevalence of temporomandibular disorders in university students' J Sci Res Publ.2012; 2 (9):1-3.

14. Vojdani M, Bahrani F, Ghadiri P. The study of relationship between reported temporomandibular symptoms and clinical dysfunction index among university students in Shiraz. Dent Res J.2012; 9 (2) :221-5.

15. Ebrahimi $M$, Dashti $H$, Mehrabkhani $M$, Arghavani M, Daneshvar-Mozafari A. Temporomandibular disorders and related factors in a group of Iranian adolescents: a cross sectional survey. J Dent Res Dent Clin Dent Prospects. 2011; 5 (4) :123-7.

16. de Oliveira AS, Dias EM, Contato RG, Berzin F. Prevalence study of signs and symptoms of temporomandibular disorder in Brazilian college student. Braz Oral Res.2006; 20 (1): 3-7.
17. Miyake R, Ohkubo R, Takehara J, Morita M. Oral parafunctions and association with symptoms of temporomandibular disorders in Japanese university students. J Oral Rehabil . 2004;31:518-23.

18. Basafa M, Shahabee M. Prevalence of tmj disorders among students and its relation to malocclusion. The Iranian Journal of Otorhinolaryngology. 2006;18:53-9.

19. Godoy F, Rosenblatt A, Godoy-bezerra J. Temporomandibular disorders and associated factors in brazilian teenagers: a cross-sectional study. Int $\mathrm{J}$ Prosthodont. 2007;20:599-604.

20. Motegi E, Miyazaki H, Ogura I, Konishi H, Sebata M. an orthodontic study of

temporomandibular joint disorders part 1: epidemiological research in Japanese 6-18 year olds. Angle Orthod. 1992;62:249-56.

21. Pereira LJ, Pereira-Cenci T, Del-Bel-Cury, Pereira sSM, Pereira AC, Ambosano GM, et al. Risk indicators of temporomandibular disorder incidences in early adolescence. Pediatr Dent . 2010;32:324-8.

22. Barbosa TDES, Miyakoda LS, Pocztaruk RDEL, Rocha CP, Gaviao MB. Temporomandibular disorders and bruxism in childhood and adolescence: review of the literature. Int $\mathrm{J}$ Pediatr Otorhinolaryngol. 2008;72:299-314.

23. Bonjardim LR, Lopes-Filho RJ, Amado G, Albuquerque RL, Goncalves SR. Association between symptoms of temporomandibular disorders and gender, morphological occlusion, and psychological factors in a group of university students. Indian $\mathrm{J}$ Dent Res 2009;20:190-4.

\section{CONTRIBUTORS}

1. Muhammad Ilyas- Concept \& Design, Data Acquisition, Data Analysis/Interpretation, Drafting Manuscript, Critical Revision, Supervision, Final Approval

2. Fariha Kifayat - Data Acquisition, Data Analysis/Interpretation, Drafting Manuscript

3. Faryal Gul - Concept and Design, Data Acquisition, Data Analysis / Interpretation, Drafting Manuscript

4. Sulman Khan- Data Analysis / Interpretation, Drafting Manuscript, Critical Revision

5. Sumaira Saeed - Concept and Design, Data Acquisition, Data Analysis / Interpretation

6. Adam Khan Danish - Concept and Design, Data Acquisition, Data Analysis / Interpretation 